\title{
cciones \\ nvestigaciones \\ Los pros y los contras de las empresas de trabajo temporal
}

\author{
Gloria TenA TENA \\ PROFESORA DEL DEPARTAMENTO DE ECONOMÍA \\ Y DIRECCIÓN DE EMPRESAS \\ ESCUELA UNIVERSITARIA DE ESTUDIOS SOCIALES \\ UNIVERSIDAD DE ZARAGOZA
}

El auge de las empresas de trabajo temporal en España es incuestionable. Su creciente importancia se refleja en el número cada vez mayor de empresas que funcionan y en el elevado número de contratos que realizan. Desde 1994, año de su legalización, no obstante, no han cesado las críticas en torno a su papel como generadoras de empleo. Este artículo trata de ahondar en el conocimiento de estas empresas y de las repercusiones de su utilización tanto para las empresas clientes como para los trabajadores temporales.

Palabras clave: empresa de trabajo temporal, ETT, empresa usuaria, trabajador temporal. 


\section{Los pros y los contras \\ de las empresas \\ de trabajo temporal}

Gloria Tena Tena

\section{Introducción}

El concepto de alquilar trabajadores a otras empresas parece ser que se originó a finales de los años 20 — se piensa que fue Workman Diversified Enterprises-, aunque autores como Moore (1965) sugieren que también pudo surgir en Inglaterra antes de la Primera Guerra Mundial. El negocio de las empresas de trabajo temporal (ETTs), sin embargo, comenzó propiamente en los años 40 cuando las empresas se dieron cuenta de las ventajas que proporcionaba una economía en expansión después de la $2^{\circ}$ Guerra Mundial. Desde entonces no ha dejado de crecer, y hacia finales de los años cincuenta estaba ya bien implantada en Estados Unidos, Países Bajos, el Reino Unido y Suiza, y al poco tiempo se extendió también a otros países de Europa occidental, como Bélgica, Francia y República Federal de Alemania.

Varios factores en la parte de la demanda parece ser que influyeron en esta primera expansión (Moore, 1965, pág. 569):

a. El incremento en la necesidad de empleados de oficina, como resultado de su escasez, con pocos desempleados en este campo y una considerable inestabilidad y rotación en el mercado laboral de estos trabajadores;

b. Ia tendencia al alza de contratar funciones especializadas fuera de las empresas;

c. el incremento de los costes laborales, tanto directos como indirectos, de contratar directamente; 
d. el hecho de que las ETTs operen en un mercado laboral diferente, y por lo cual pueden substraerse de una parte substancial de estos incrementos;

e. y el espíritu empresarial de los individuos que promocionaron la idea.

Desde el lado de la oferta, el hecho de que la fuerza laboral pudiera proporcionar los trabajadores se explica por el incremento de la participación de la mujer en el mercado laboral.Las ETTs principalmente proveyeron un canal para acentuar ese incremento, ofreciendo oportunidades para aquellos/as que no querían, o no podían, trabajar en un trabajo regular. Según Moore (1965, pág. 569), el papel principal de los pioneros del trabajo temporal, principalmente, fue el de crear una industria que activó esas fuerzas latentes.

Fundamentalmente, el desarrollo de las ETTs en los países industrializados, especialmente en USA, se lleva a cabo entre los años 1960 y 1980. Es a partir de 1965, cuando se suscita en el seno de la Organización Internacional del Trabajo un debate acerca de la conveniencia o no de este tipo de empresas. Se trataba entonces de guiarse por dos planteamientos básicos: proteger a los trabajadores de la explotación que puede producir la existencia y actuación de intermediarios en el mercado de trabajo y garantizar el papel activo del Estado.

La situación del trabajo temporal en Europa, en general, ha tenido muy poco que ver con la situación española. Muy al contrario de la ilegalidad en la que ha subsistido este sistema en nuestro país hasta épocas recientes, la mayoría de los Estados de la Unión Europea han legislado sobre este tipo de servicios a partir de los años 60, o bien los han permitido sin disponer de una normativa específica al respecto.

La primera ley nacional europea circunscrita a regular las operaciones de estas empresas fue la holandesa, en 1965, que ha tenido una influencia capital en los textos posteriores de los demás países. Más tarde, en los primeros años de la década de los setenta, Francia y Alemania se sumaban a esta iniciativa. Los últimos en hacerlo fueron Italia, en 1992, y España, en 1994, con una ley modificada en 1999. 


\section{Las empresas de trabajo temporal en España}

La trascendencia que han adquirido las empresas de trabajo temporal en nuestro país se ve reflejada en cifras: realizaron 1,8 millones de contratos en 1998, lo que representa un incremento del 37,8\% con respecto a 1997; los contratos de puesta a disposición, en las dos modalidades de interinidad que se contemplan para las ETTs, ascendieron a 135.800 y representaron un $23 \%$ del total de contratos eventuales registrados. Esta cifra supone un incremento significativo con respecto al $21 \%$ que representaban en 1997, y sobre todo en relación con el $14 \%$ de 1996.

La memoria del Consejo Económico y Social (CES) ofrece otro dato revelador, cifra en 438 las ETTs existentes en España a finales del año pasado (según datos de noviembre de 1999 serían ya 452). Las cesiones de trabajadores sumaron 1.247.523, prácticamente el doble de las que se produjeron durante 1996.El incremento del número de empresas se ha producido paralelamente a un notable proceso de fusión y concentración que ha afectado a diversas e importantes entidades. Si por un lado podemos hablar de la especialización de las empresas de trabajo temporal, por el otro cabe destacar la concentración que se está produciendo en el sector. Las ETTs se están especializando en sectores para concentrar la oferta, tanto de personas como de puestos de trabajo, pero también observamos como muchas pequeñas empresas desaparecen si no se fusionan con otras, y el predominio de las grandes empresas, muchas de ellas internacionales, es notable.

El alcance de estas empresas en nuestro país es indudable, esto es aún más significativo si pensamos que su crecimiento se ha producido en pocos años. Convendría remontarnos a sus orígenes, analizar las causas que propiciaron su implantación y ver como es su marco de actuación actual, porque todo ello nos puede ayudar a su mejor comprensión.

Las ETTs figuran en diversos ordenamientos jurídicos nacionales desde hace más de un cuarto de siglo. Pero la contratación de trabajadores con la finalidad de cederlos con carácter temporal a otras empresas había estado tradicionalmente prohibida por los ordenamientos laborales, y considerada como tráfico ilegal de mano de obra. Pese a ello el fraude era gene- 
ralizado. ${ }^{1}$ Se había pretendido impedir esta cesión, considerada como perniciosa y nociva, a través de un aparato sancionador para los supuestos de incumplimiento de la interdicción legal, y de mecanismos de garantía de los derechos de los trabajadores afectados.

En los noventa, con la nueva problemática social, y la irrupción de nuevas modalidades de contratación en Europa, el Real Decreto 18/1993, de 3 de diciembre, sobre medidas urgentes de fomento de la ocupación, deroga expresamente el artículo 43 del Estatuto de los Trabajadores, por la que la cesión pasa a ser lícita, estableciendo en su artículo 2:

1. La contratación de trabajadores para cederlos temporalmente a otra empresa sólo podrá efectuarse a través de empresas de trabajo temporal debidamente autorizadas en los términos que legalmente se establezcan.

2. Los empresarios que infrinjan lo señalado en el apartado anterior responderán solidariamente de las obligaciones contraídas con los trabajadores y la seguridad social, sin perjuicio de las demás responsabilidades, incluso penales, que procedan por dichos actos.

3. Los trabajadores sometidos al tráfico prohibido tendrán derecho, a su elección, a adquirir la condición de fijos en la empresa cedente o cesionaria, una vez transcurrido un plazo igual al que legalmente se ha podido fijar para el periodo de prueba.

Se trata indiscutiblemente del primer gesto de apertura de la legislación a la posibilidad de las ETTs, que las plantea en esta Ley como únicas canalizadoras de la cesión temporal. No obstante, resultaría ingenuo pensar que en este primer momento de regulación normativa, el mercado de las ETTs no registraba actividad. En realidad, desde antes de 1990 determinadas empresas, especialmente multinacionales del sector, habían venido preparando su futura implantación en nuestro país, y funcionando de modo más o menos paralegal como consultoras de selección o de formación, o como prestadoras de servicios a empresas bajo forma de subcontratas.

1 En España, de hecho estarían funcionando estas empresas ya desde aproximadamente 1980 (Albizu, 1997). 
¿Por qué este cambio de actitud con respecto a las ETTs? Fue debido a las propias características del mercado de trabajo de los años setenta y ochenta, concretamente a una serie de causas ambientales como son las señaladas por Carlos Ongallo:

-Por la situación de hecho que se estaba dando en España, donde en realidad las ETTs encubiertamente estaban ya funcionando.

- Por la existencia de unos índices económicos negativos, protagonizados por la tasa de paro, estimable en $1 / 5$ del total de la población activa.

- Y por el fracaso reconocido de los servicios públicos de colocación (citado en Puchol, 1997, pág. 140).

Las empresas de trabajo temporal se rigen en la actualidad por la Ley 14/1994, de 19 de Mayo, modificada por la Ley 29/1999, de 16 de Julio. Asimismo, se rigen también por el Convenio Colectivo aplicable a dichas empresas.

El Convenio Colectivo tiene gran importancia porque en él se determinan las condiciones de trabajo por las que se van a regir los trabajadores cedidos: supuestos de contratación, clasificación profesional, periodo de prueba, contenido de la prestación laboral, jornada de trabajo, jornada nocturna, retribución, horas extraordinarias, descanso, vacaciones, faltas y sanciones, movilidad del trabajador, modificación de las condiciones de trabajo y extinción del contrato de trabajo, entre otras.

Para que una ETT pueda ejercer su actividad necesita la autorización de la Administración Laboral, que es la que lleva también el registro de tales empresas. La autorización inicial tiene una validez de un año, pudiendo prorrogarse por dos periodos anuales más; transcurridos los cuales la autorización se concede sin límite temporal. La autorización se concede a la empresa de forma global, para todas las oficinas que tiene en el país.

\section{Naturaleza de las empresas de trabajo temporal}

La naturaleza de una empresa de trabajo temporal viene condicionada por su definición legal: son empresas cuya actividad consiste en poner a disposición de otra empresa, denomi- 
nada empresa usuaria, con carácter temporal, trabajadores por ella contratados, para que puedan hacer frente a necesidades también temporales.

Sin embargo, el hecho que realmente define la actividad de una ETT no es la temporalidad de los trabajadores, sino el que los trabajadores sean contratados por ella para posteriormente ser cedidos a una tercera empresa - empresa usuaria - donde desarrollarán su trabajo y quedarán bajo su ámbito de organización y dirección del trabajo.

Es esta cesión de trabajadores lo distintivo de las ETTs con respecto a la relación laboral ordinaria — donde cada trabajador contrata libremente sus servicios con un empresario, que es quien organiza y dirige el trabajo, abona su salario a los empleados, y mantiene la potestad disciplinaria sobre ellos-. Aquí se establece una relación triangular — trilateralidad, tal como la han denominado autores como Alcaide, González y Flórez (1996)—, en la que la empresa usuaria abona una cantidad a la ETT a cambio de los servicios del trabajador cedido, quien acudirá al puesto de trabajo en la empresa usuaria, atenderá a las instrucciones de los encargados de esta empresa y realizará su trabajo en las condiciones que determine dicha empresa; la ETT será el verdadero empresario del trabajador cedido (el contrato de trabajo, no se olvide, se habrá firmado entre el trabajador y ETT), será quien le abone su salario, y mantendrá el poder disciplinario y sancionador sobre él.

Como la actividad de una ETT es la contratación de trabajadores con la finalidad de cederlos con carácter temporal a otras empresas, sus funciones básicas serán: captar a empresas usuarias que requieran los servicios que la ETT ofrece; seleccionar a los trabajadores; formarles; contratarles y retribuirles.

A nivel general, y una vez la empresa usuaria ha dado la aprobación del trabajador puesto a disposición por la empresa de trabajo temporal, esta última debería seguir unos pasos determinados, como son el acompañamiento y presentación del candidato en la empresa usuaria, control de la primera adaptación del trabajador en su puesto de trabajo, seguimiento del periodo de prueba, y evaluación de la calidad del trabajador y del servicio (Sánchez de León, 1995). 
Entre el trabajador y la ETT se formaliza un contrato de trabajo, que puede ser de duración indefinida ${ }^{2}$ o temporal. Con la empresa usuaria, la ETT realiza un contrato mercantil, llamado contrato de puesta a disposición. Este solamente se puede realizar para satisfacer necesidades temporales de personal en los siguientes supuestos (Moradillo Larios, 1996, pág. 67):

a. Para la realización de una obra o servicio determinado cuya ejecución aunque limitada en el tiempo es, en principio, de duración incierta.

b. Para atender las exigencias circunstanciales del mercado, acumulación de tareas o exceso de pedidos (picos de trabajo), aun tratándose de la actividad normal de la empresa, y con una duración máxima de seis meses.

c. Para sustituir a trabajadores de la empresa con derecho a reserva del puesto de trabajo (enfermedad, vacaciones, excedencia). Su duración coincidirá con el tiempo durante el cual subsista la causa que motivó el respectivo contrato. Se extinguirá en el momento en que el trabajador sustituido se reincorpore a la empresa, o bien cuando se extinga la relación laboral entre la empresa y el sustituido.

d. Para cubrir de forma temporal un puesto de trabajo permanente mientras dure el proceso de selección o promoción. Su duración máxima será de tres meses.

\section{4. ¿Por qué las empresas recurren a las empresas de trabajo temporal?}

Diferentes factores han contribuido tanto al aumento de la demanda como de la oferta de trabajadores temporales. Las condiciones económicas, los avances tecnológicos, las normas sociales y los aspectos legales han influido tanto en las empresas como en los individuos. Es importante revisar las razones que tiene cada parte para participar en esta estructura de trabajo dado que la racionalidad que hay detrás de la acción puede afectar a la naturaleza de la experiencia laboral.

2 Con la reforma de la ley en 1999, es obligatoriedad por parte de las ETTs el contratar con carácter fijo a 12 trabajadores por cada 1000 contratos que realicen. 
Utilizar los servicios de una empresa de trabajo temporal conlleva una serie de ventajas para las empresas contratantes: la empresa que contrata al trabajador no tiene problemas de absentismo laboral; se observa una disminución de los trámites administrativos; se libran de la responsabilidad del proceso de reclutamiento y selección que puede resultar incómodo (Rowan, 1994) y para el cual no suelen disponer de tiempo ni de la competencia necesaria; las empresas pueden ajustar mucho más, a nivel de días y horas, las necesidades de personal que tienen, muy en relación con la producción y con la oferta y la demanda de su producto o servicio; y el personal facilitado por las ETTs está preparado y formado para cubrir las vacantes o las necesidades que tienen puntualmente las empresas ${ }^{3}$. Todas estas ventajas cumplirían con el objetivo principal que las empresas pretenden satisfacer a través de la contratación de las ETTs, y que según Hernando Moreno (1996, pág.29) «fundamentalmente es disponer de un valioso instrumento de flexibilidad en la gestión de los recursos humanos temporales».

Pero posiblemente sea la contención de los costes una de las principales razones por las que las empresas utilizan trabajadores temporales contratados a través de ETTs ${ }^{4}$. El salario por hora que la empresa paga a la ETT por el trabajador, puede en realidad igualar o incluso superar al que paga a su personal fijo, especialmente para trabajadores cualificados. No obstante, la empresa que utiliza al personal temporal de una forma correcta puede reducir costes laborales eludiendo otros gastos adicionales: los asociados con el proceso de reclutamiento, formación, beneficios, tiempos muertos. Este último factor, en particular no retribuir los tiempos no productivos-, puede ser el que más costes ahorre (Coates,1988). Además de lo anterior se convierte un coste fijo en coste variable, con lo cual se produce una dis-

${ }^{3}$ Esta afirmación es puesta en entredicho por diversos estudios:en el llevado a cabo por Sáenz (1996), las empresas usuarias no demostraban plena satisfacción con la formación dada a los trabajadores temporales por parte de las ETTs;según los datos recogidos por Baeza Tordesillas(1997a), el 76,2\% de los trabajadores temporales afirmaban no haber recibido ningún tipo de formación.

${ }_{4}$ Fuentes del sector de las ETTs consideran que la contratación de un trabajador a través de una ETT, con la reforma de la ley en julio del 99, se encarece el coste laboral como media entre un $10 \%$ y un $20 \%$ lo cual elimina las ventajas del menor coste que hacía útil la relación de las empresas con las ETTs. 
minución de las cargas salariales para la empresa (Baeza Tordesilla, 1997b).

Bronstein (1991) indica, por su parte, que las empresas aducen diferentes razones por las que recurren a las ETTs :

"Las mas corrientes son la necesidad de sustituir a trabajadores permanentes que se hallan ausentes (sobre todo es para el relevo de trabajadoras que disfrutan de licencia por maternidad), la ejecución de tareas ocasionales o de trabajos que requieren una cierta competencia técnica de la que el usuario no dispone, y las «crestas» de actividad, estacional o coyuntural. A menudo, las empresas usuarias reconocen también que acuden a una ETT para que ésta les facilite un trabajador temporal con miras a cubrir, llegado el caso, un puesto permanente que ha quedado vacante.» (pág. 491)

Una representante del sector de las ETTs (M. Miranda, 1994, pág.83) señala que los mayores beneficios derivados del uso de personal temporal lo obtienen las empresas que tienen un negocio cíclico, con demanda estacional, es decir, aquellas cuyo volumen de trabajo, producción, distribución o ventas experimenten fluctuaciones a lo largo de semanas, meses o épocas del año. Dado que les proporciona la flexibilidad necesaria en función de la evolución de las demandas del mercado, al poder disponer del personal necesario en el momento en que se necesita.

\section{5. ¿Por qué los trabajadores recurren al empleo temporal?}

La opinión generalizada es que las personas aceptan trabajos eventuales sólo porque no pueden encontrar trabajos fijos. Esto es indudablemente verdad para muchos trabajadores, pero determinadas personas pueden preferir trabajos temporales.

Así, Maniscalco (1992) argumenta que:

«Las razones por las cuales una persona llega a ser trabajador temporal son tan diferentes como diferentes son las personas, yendo desde querer un trabajo con horarios, días o periodos flexibles; a querer un trabajo en diferentes lugares del país y en diferentes estaciones del año; a querer permanecer ocupado en la jubilación; a necesitar alguna clase de trabajo por estar en paro o debido a la falta de empleos fijo.» (pág. 67) 
Por lo tanto, bajo la etiqueta de «eventuales» se oculta una gran variedad de personas y sus motivaciones son muy diversas. Hay quien busca trabajo fijo y quién sólo intenta cubrir unas vacaciones hasta que empiece el nuevo curso, y retirados en busca de un ingreso extra, y madres jóvenes que toman un empleo a jornada parcial para no desvincularse totalmente del mundo del trabajo hasta tanto los hijos tengan edad suficiente. Determinados comentaristas mantienen que condiciones de trabajo como estas no deberían ser tan cuestionadas porque son bien recibidas especialmente por el colectivo de mujeres casadas, que valoran su flexibilidad y que no desean un trabajo fijo y a tiempo completo (otros autores no comparten este punto de vista.Ver p.ej., Hakim, 1995, 1996, 1998; Crompton y Harris, 1998).

Algunos trabajadores temporales consideran los empleos de duración limitada meramente como la fuente de ingresos que les permita mantener un pasatiempo o un modo peculiar de vivir. Otros se plantean el trabajo temporal como una oportunidad para ampliar horizontes y conocer empresas y gentes diversas. Estas personas, también, pueden perseguir el trabajo temporal porque les atrae la libertad de entrar y salir de las relaciones de empleo, y la flexibilidad que el trabajo temporal permite (Smith 1997, pág. 26).

Polivka y Nardone (1989), también indican que muchos trabajadores pueden necesitar horarios más flexibles que los que proporcionan los trabajos permanentes. Por ejemplo, los padres que tienen hijos pequeños pueden querer trabajar sólo durante las horas de colegio o durante el periodo escolar.Y los estudiantes que quieran sólo trabajar en periodo no lectivo, o personas que tengan que cuidar a familiares ancianos. Por lo tanto, y a fin de ganar esta flexibilidad, los trabajadores pueden querer trabajos temporales. Aparte de una variedad de razones muy amplia que pueden tener los trabajadores para aceptar esta relación laboral, estos autores igualmente admiten que hay un grupo que, por decantación personal, simplemente quieren trabajar como temporales por la libertad e independencia que les proporciona.

Lo anterior es corroborado por la Organización Internacional de Trabajo en un estudio sobre la situación laboral en Europa en el que se concluye que:

«Para un $30 \%$ de los trabajadores temporales..., [el] empleo temporal es su primera alternativa (jóvenes, nómadas, personas con res- 
ponsabilidades familiares, trabajadores especializados como enfermeras, traductores).» (Rowan, 1994: 52)

En lo que respecta a los trabajadores temporales que van en busca de un empleo estable, y que según las palabras de Durán López (1994, pág. 30) el empleo temporal sería para ellos «una fórmula de espera de un empleo permanente», pueden pertenecer por lo menos a dos grupos:

1. los que esperan adquirir, a través del trabajo temporal, la experiencia que les falta para conseguir un empleo permanente y que ven en ese tipo de trabajo un trampolín para su inserción profesional

2. los que se atascan en el trabajo temporal porque tan sólo se les propone misiones de más o menos corta duración, y que aceptan a falta de otra cosa mejor. En este último grupo, para los que el empleo temporal no es una solución óptima y además es una elección totalmente involuntaria, es donde hallamos la precariedad socialmente más preocupante, y no sorprende que encontremos en esa categoría una mayoría de trabajadores de edad, poco o nada cualificados, de inmigrante o de amas de casa que desean retornar al trabajo.

Es difícil disponer de cifras precisas sobre la proporción que corresponde a cada categoría en el total de los trabajadores temporales, y los porcentajes propuestos son muy variables. Según ciertas encuestas, casi un tercera parte de los temporales no parecen desear un empleo permanente, los resultados del estudio de Baeza Tordesillas (1997 a) concluyen que el 20,8 \% de estos trabajadores se encontraría en este grupo; de un 30 a un $40 \%$ acceden efectivamente a un empleo estable al cabo de una o varias misiones de trabajo temporal. ${ }^{5}$ De lo dicho se desprende que la precarización involuntaria sólo afectaría a un tercio del total de los temporales, ${ }^{6}$ lo que no es demasiado en comparación con la que resulta de otras formas de empleo atípico.

${ }^{5}$ Según un estudio de Sáez (1996) sólo alrededor del 16\% de los trabajadores temporales cedidos en misión pasarían a formar parte de la plantilla estable de la empresa usuaria.

${ }^{6}$ De acuerdo con los datos de la OIT representarían del $30 \%$ al $40 \%$ del total de trabajadores temporales (Rowan, 1994, págs.52-53). 


\section{Los contras de las empresas de trabajo temporal}

Por el lado de la empresa usuaria, y aunque en general, se beneficia del apoyo que le da la ETT —esto es confirmado en el estudio de Hernando Moreno (1996, pág. 30) sobre empresas del sector financiero en el que una elevada proporción de empresas (55,6\%) manifiestan la utilidad de la existencia de ETTs - no nos podemos olvidar, no obstante, de los efectos negativos que puede tener para la empresa usuaria la contratación de trabajadores temporales. ${ }^{7}$ Tal como señalan Bednarski y Kleiner (1993), muchos de estos trabajadores crean división, animosidad, y bajan la moral en el lugar de trabajo. "Se sienten como si fuesen una herramienta, y no como una parte de la organización.» (pág. 84)

Otro aspecto a destacar es la escasa inversión que suelen hacer las ETTs en la formación y entrenamiento de los trabajadores temporales -aunque recordemos que por Ley está obligada a destinar el 1,25\% de su masa salarial anual a formación-, y la consecuencia a menudo son trabajadores poco entrenados para realizar las tareas que se les encomiendan en la empresa usuaria, lo que a su vez da como resultado frecuentes errores e interrupciones en el trabajo. Todo ello puede afectar a la empresa haciéndola menos eficiente y menos competitiva, irónicamente en una época en que la eficiencia y la competitividad se consideran tan importantes.

Siguiendo con las posibles desventajas que puede tener la contratación de personal de ETTs nos encontramos con el impacto que puede tener sobre la cultura de la empresa, que tal como señala Husted (1997)vendría dado porque «...el trabajador temporal [actualmente] puede tener condiciones distintas a los que realizan el trabajo de igual valor en la empresa usuaria» (pág. 41). Esta realidad se confirma con los datos proporcionados por Baeza Tordesilla(1997a), que reflejan que una tercera parte de los trabajadores temporales ven un trato claramente diferenciado con respecto al personal de plantilla.Husted (1997,

7 Hay que puntualizar que la mayoría de los efectos negativos que se derivan de la contratación de trabajadores temporales a través de ETTs se deben generalizar también a la contratación directa. 
pág. 41), basándose en la teoría de justicia de la psicología social de Adams (1965), argumenta que no puede haber conformidad en los trabajadores temporales ya que no reciben el mismo trato o remuneración que los trabajadores fijos no obstante haber hecho el mismo trabajo. Esta no conformidad daría como consecuencias un desempeño rutinario e indiferente (Sheppard, Lewicki y Minton, 1992), y todo ello influiría negativamente en la cultura empresarial. Aún más, Husted (1997), siguiendo los postulados de O’Reilly (1989), concluye:

«No se puede lograr un sentimiento de pertenencia y de compromiso por parte de los trabajadores [temporales]. Los trabajadores temporales harán solamente lo justo, y nada más. Puede ser que la empresa usuaria esté de acuerdo con que el trabajador temporal haga nada más que lo justo. Pero hay que cuestionar las bases de competencia de esta empresa ya que hoy en día los valores como la calidad son básicos para la competitividad de la empresa y se logra solamente con una actitud de pertenencia por parte de todos los empleados.» (pág. 41)

Por el lado del trabajador temporal, los contras de las ETTs se ven reflejados esencialmente en las críticas hechas por las principales centrales sindicales. $Y$ si bien es verdad que en sus orígenes tropezó con la oposición rotunda de estos sindicatos en la actualidad se muestran menos hostiles, pues sus objeciones se centran cada vez más en los riesgos de abuso o de fraude y menos en el trabajo temporal propiamente dicho.

Las denuncias generalizadas se refieren, substancialmente, a la frecuencia con que el trabajador cambia de un trabajo a otro propiciada por la duración de los contratos. En el año 1998 del medio millón de contratos que se realizaron a través de ETTs el $75 \%$ de ellos a menores de 29 años- algunos duraron dos o tres días. Nada extraño si se tiene en cuenta que el $55 \%$ de los contratos firmados se alargaron un mes como máximo, y el $39 \%$ sólo entre uno y cinco días.

La elevada tasa de siniestralidad que arrojan las personas contratadas por ETTs, es otra de las críticas que se le hacen a estas empresas. Aunque, desde el lado de las ETTs, y más concretamente desde la FEDET (agrupa a 60 pequeñas y medianas empresas del sector), se señala que «la regulación española es la más exigente en materia de prevención de riesgos laborales, tanto con la ETT como con la empresa usuaria». 
Y según la ley, los sectores en los que la actividad laboral implica un riesgo elevado no pueden hacer uso de las ETTs. La realidad es, según denuncian los sindicatos, que la tasa de accidentes laborales es cuatro veces mayor que en la del resto de trabajadores ${ }^{8}$. Esta situación, aducen, se debe principalmente a la poca preparación de los trabajadores por las empresas que ofrecen empleo temporal.

\section{Conclusiones}

La imagen que emerge de la descripción hecha del trabajo temporal relacionado con las ETTs es cuando menos compleja. En primer lugar, porque difiere en importantes aspectos del tradicional trabajo fijo (p. ej. con respecto a la retribución, contenido del trabajo, estabilidad y seguridad del empleo). Igualmente llamativo es la substancial evidente varianza que hay entre los trabajadores temporales con respecto a sus características y motivaciones para perseguir el trabajo temporal. El colectivo de trabajadores temporales incluye personas con una amplia diversidad de preferencias y necesidades, las cuales sugieren que habrá una importante variabilidad cuando se busque predecir respuestas al empleo temporal.

Por otra parte, la poca tradición de estas empresas en nuestro país a causa de su no muy lejana legalización, y la falta de una legislación más estricta ha generado situaciones de abuso que han llevado a cuestionar a esta clase de empresas. No obstante, es indudable que esta relación laboral va ganando terreno y no debemos olvidar, sin dejar de lado sus aspectos negativos, que la realidad es que las ETTs representan en la actualidad para determinados colectivos (jóvenes, desempleados de larga duración, etc.), la única manera rápida y eficaz que tienen de acceder al mundo laboral.

${ }^{8}$ En este sentido, durante 1998 en Aragón, veinte empresas de trabajo temporal que ocuparon de media a 1078 trabajadores, registraron 276 accidentes, lo que arroja una tasa de 256 accidentes por cada 1000.La cifra es significativa si tenemos en cuenta que a nivel general, durante el año pasado, hubo 63 accidentes por cada 1000 trabajadores. 


\section{Referencias bibliográficas}

ALBIZU, E. (1997): Flexibilidad Laboral y Gestión de los Recursos Humano. Ariel, Barcelona.

ALCAIDE CASTRO, M.; GONZÁLEZ RENDÓN, M. y FLÓREZ SABORIDO, L. (1996): Mercado de trabajo, reclutamiento y formación en España. Pirámide, Madrid.

BAEZA TORDESILLAS, J. M. (1997 a): Encuesta sobre las acti tudes de los trabajadores de las empresas de trabajo tempo ral. Instituto de Empresa.

- (1997 b): Las empresas de trabajo temporal. Nota técnica publicada por el Departamento de Investigaciones del Instituto de Empresa.

BEDNARSKI, P. y KLEINER, B. H. (1993): "Contingency Workers: Short-Term Boon, Long-Term Bane?». Journal Of Business And Society, ํ‥ 6, págs. 82-89.

BRONSTEIN, A.S. (1991): «Temporary work in Western Europe: Threat or complement to permanent employment?». International Labour Rewiew, № 130, págs. 291-310.

COATES, V. T. (1988): "Office automation technology and contingent work modes». Flexible workstyles: A look a contingent labor.Women's Bureau, U.S. Deparment of Labor, Washington.

DURÁN LÓPEZ, F. (Septiembre, 1994): «La función económicosocial de las empresas de trabajo temporal». Capital Humano, n. ${ }^{\circ} 70$ Extra Trabajo Temporal, págs. 28-30.

HERNANDO MORENO, M. (Septiembre, 1996): «Estudio sobre las necesidades de trabajo temporal en el nuevo entorno competitivo del sector financiero español». Capital Humano, №. 92, págs. 8-34.

HUSTED, B. (Septiembre, 1997): «La Ética y las empresas de trabajo temporal: Un enfoque rawlsiano». Capital Humano, n. ${ }^{\circ} 103$ Extra Trabajo temporal, págs. 38-43.

MANISCALCO, R.(Marzo, 1992):High-tech temps in supply and demand. HR Magazine, págs. 66-67.

MIRANDA, M.(Noviembre-Diciembre, 1994):El trabajo temporal una clave para la competitividad. Dirección y Progreso, no 138, págs. 81-83.

MOORE, M. (1965): «The temporary help service industry: Historical development, operation, and scope». Industrial and Labor Relations Review, № 64, págs. 555-569. 
MORADILLOS LARIOS, C. (1996): Los contratos de trabajo tem porales e indefinidos:Incentivos a la contratación. CISS S. A., Valencia.

ONGALLO, C. (3 $3^{a}$ edición, 1997): «El trabajo temporal». En PUCHOL, L., Dirección y Gestión de Recursos Humanos, págs. 136-148. Díaz de Santos, Madrid.

POLIVLA, A. E. y NARDONE, T. (Diciembre, 1989): «On the definition of "contingent work"». Monthly Labor Review, págs. 9-16.

RAWLS, J. (1971): A theory of justice. Harvard University Press, Cambridge, MA.

ROWAN, M. (Septiembre, 1994): «Formación para el trabajo temporal, un nuevo desafío». Capital Humano, №.70, págs. 50-62.

SÁEZ, M. T. (Septiembre, 1996): «Estudio comparativo sobre necesidades de trabajo temporal por sectores». Capital Humano, no. 92 Extra Trabajo Temporal, págs. 36-41.

SÁNCHEZ DE LEÓN, L. (Marzo-Abril, 1995): «Las empresas de trabajo temporal como nueva herramienta de gestión». Dirección y Progreso, no 140, págs. 65-67.

SHEPPARD, B. H.; LEWICKI, R. J. y MINTON, J. W. (1992): Organizational justice: The search for fairmess in the work place. Lexinton Books, New York.

SMITH, D. (1997): El Mundo del Trabajo Temporal. Martínez Roca, Barcelona. 